\title{
Effectiveness of Assertive Case Management for Patients with Suicidal Intent Admitted to Emergency Departments Following Attempted Suicide by Self-Poisoning: A Secondary Analysis of the ACTION-J Study
}

\author{
Masami Inui-Yukawa \\ Department of Psychiatry, Kitasato University, School of Medicine https://orcid.org/0000-0002-8323-910X \\ Hitoshi Miyaoka \\ Department of Psychiatry, Kitasato University, School of Medicine \\ Kenji Yamamoto ( $\nabla$ key@is.icc.u-tokai.ac.jp) \\ https://orcid.org/0000-0002-0031-9068 \\ Yoshito Kamijo \\ Department of Emergency Medicine, Faculty of Medicine, Saitama Medical University \\ Michiko Takai \\ Department of Emergency Medicine, Faculty of Medicine, Saitama Medical University \\ Naohiro Yonemoto \\ National Center of Neurology of Psychiatry, Department of Public Health, Juntendo University School of Medicine \\ Chiaki Kawanishi \\ Department of Neuropsychiatry, Sapporo Medical University Graduate School of Medicine \\ Kotaro Otsuka \\ Department of Neuropsychiatry, School of Medicine, Iwate Medical University \\ Hirokazu Tachikawa \\ Department of Disaster and Community Psychiatry, Faculty of Medicine, University of Tsukuba \\ Yoshio Hirayasu \\ Hirayasu Hospital
}

Research article

Keywords: Emergency medicine, Self-harm, Self-poisoning, Suicide attempt, Assertive case management intervention

Posted Date: July 14th, 2020

DOI: https://doi.org/10.21203/rs.3.rs-38646/v1

License: () (1) This work is licensed under a Creative Commons Attribution 4.0 International License. Read Full License

Version of Record: A version of this preprint was published at Psychiatry Research on October 1st, 2021. See the published version at https://doi.org/10.1016/j.psychres.2021.114125. 


\section{Abstract}

Background: Self-poisoning is commonly observed in individuals as a component of suicide attempts and self-harm. The effectiveness of interventions for self-poisoning is unclear. The objective of this study was to examine the effectiveness of assertive case management intervention in preventing suicidal behaviour in self-poisoning patients.

Methods: We conducted a secondary analysis of data from the ACTION-J study. Participants were self-poisoning patients with clear suicidal intent who were admitted to emergency departments and who had a primary psychiatric diagnosis (as per DSM-IVTR axis 1). Patients were randomly assigned either to assertive case management (intervention group) or enhanced usual care (control group). The primary outcome measure was the incidence of a first recurrent suicidal attempt within 6 months after group assignment.

Results: There were 297 self-poisoning patients in the intervention group and 295 in the control group. The primary outcome was significantly lower in the intervention group than in the control group (risk ratio [RR]: $0.473,95 \%$ confidence interval [CI]: 0.284 to 0.788). The incidence of a first recurrent suicidal attempt within 1 and 3 months after group assignment was also significantly lower in the intervention group, as was the number of overall self-harm episodes over the entire study period (incidence rate ratio [IRR]: $0.711,95 \% \mathrm{Cl}: 0.582$ to 0.866$)$. Furthermore, the number of non-suicidal self-harm episodes and suicide attempts was significantly lower in the intervention group than in the control group.

Conclusion: Assertive case management is effective when promptly introduced in a hospital setting as an intervention following a suicide attempt, particularly for self-poisoning patients.

Trial Registration: This study is registered at ClinicalTrials.gov (NCT00736918) and UMIN-CTR (C000000444).

\section{Background}

Self-poisoning is one of the most common methods observed in suicide attempts and self-harm. A self-poisoning episode is defined as the self-exposure of an individual to an amount of a substance associated with significant potential to cause harm. The term 'self-poisoning' has been used to refer to a type of self-harm without suicidal intent as well as a method of attempted suicide with some intent to die [1, 2].

According to data collected from emergency departments at hospitals, self-poisoning accounts for $67 \%$ of attempted suicides and self-inflicted injuries in the United States [3], 78\% of non-fatal self-harm episodes in the United Kingdom [4], and 86\% of deliberate self-harm episodes in Sweden [5].

Several interventions have been developed to specifically target self-poisoning patients. These include postcard interventions [69], a telephone-based intervention [10], and a brief psychological intervention [11]. Unfortunately, the effectiveness of these interventions is unclear, and inconsistencies in methodologies and designs across studies make comparisons difficult (Table 1).

Against this backdrop, the present study aimed to determine whether an assertive case management intervention reduced suicidal behaviour in self-poisoning patients as a secondary analysis of the ACTION-J study [12-14].

\section{Methods}

\section{Study design and participants}

The ACTION-J study was a multicentre randomized controlled trial carried out in the emergency and psychiatric departments of 17 general hospitals in Japan. Details of the ACTION-J study have been published previously $[12,13]$. We conducted a secondary analysis of data from the ACTION-J study in order to examine the effectiveness of assertive case management in preventing suicidal behaviour in self-poisoning patients.

Participants (aged $\geq 20$ years) were self-poisoning patients with clear suicidal intent who were admitted to emergency departments after attempting suicide between July 1, 2006, and December 31, 2009, and with a primary psychiatric diagnosis (as 
per DSM-IV-TR axis 1). Intention in anticipation of death was confirmed at least twice using the Suicide Intent Scale [15]. In this study, self-poisoning patients were identified as those who had attempted suicide using pharmaceutical drugs prescribed to them by a medical doctor, over-the-counter drugs, or poison products. Participants were randomly assigned to either assertive case management (the intervention group) or enhanced usual care (the control group). All participants provided written informed consent prior to registration.

The study protocol was approved by the Central Research Ethics Committee of the study sponsor (Japan Foundation for Neuroscience and Mental Health, Tokyo, Japan) and by the local ethics committees of all participating hospitals. This study is registered at ClinicalTrials.gov (NCT00736918) and UMIN-CTR (C000000444).

\section{Interventions}

Participants in the intervention group were provided with assertive, continuous case management by case managers trained by mental health professionals. The main contents of case management were as follows: planning regular interviews (either face-toface or by phone), collecting information on the background and treatment status of each patient and making an assessment, offering encouragement to seek psychiatric treatment and provision of psychoeducation, coordinating appointments with psychiatrists and primary care physicians, and use of social resources. Participants received periodic interviews at 1 week and at $1,2,3,6,12$, and 18 months after group assignment, which included their hospitalization period and/or period after discharge. After further consent, participants continued the interviews every 6 months until the end of the study period (June 30, 2011). When case managers were unable to contact participants, they contacted family members who also provided informed consent. Participants were allowed to contact case managers by phone or to arrange face-to-face meetings in accordance with their needs, mental state, or any psychosocial issues, irrespective of the specific approaches described above.

The control group was provided with enhanced usual care which entailed physical and psychiatric treatment, psychoeducation, emergency crisis intervention as needed, and case management during hospitalization. In addition to standard psychiatric treatment, a semi-structured psychoeducational program was provided, which included discussions of psychological changes leading to suicide, risk factors for suicide, and the relationship of suicide with psychiatric disorders. As these case management interventions had not been previously offered in emergency departments, the control group received care that was better than what is typically offered in clinical practice in Japan. Thus, we defined the control intervention as "enhanced usual care," and the experimental intervention as assertive case management since case management had been provided continuously even after participant discharge. An information leaflet was provided to both groups at every outcome assessment visit.

\section{Outcomes}

The primary outcome was the incidence of a first recurrent episode within 6 months after group assignment. This outcome was chosen because the ACTION-J study found a significant reduction in the incidence of first recurrent suicidal behaviours during the same period [13], and a separate investigation showed a significant reduction in suicidal ideation [11].

The secondary outcome was the number of repeat overall self-harm episodes during the study period (follow-up period of 18 months to 5 years). This outcome was chosen because a previous secondary analysis of data from the ACTION-J study showed a significant decrease in the overall number of incidents following the intervention [14]. Furthermore, a previous study by Hassanian-Moghaddam et al. showed a significant reduction in the number of suicide attempts during follow-up [9]. We additionally investigated the incidence of a first recurrent episode within 1,3,12, and 18 months after group assignment, as well as the number of repeat suicide attempts and non-suicidal self-harm episodes.

The outcome assessors, who were independent and masked to group assignment, collected information about suicide attempts and non-suicidal self-harm episodes from participants or their family members via direct interviews. Outcome evaluations were performed face-to-face or by telephone interviews 6 and 18 months after group assignment, and then annually until the end of the study period. Using information obtained by outcome assessors, a masked event review committee classified and confirmed every self-harm episode as being either a suicide attempt or a non-suicidal self-harm episode.

\section{Statistical analysis}


Analyses were conducted in accordance with the intention-to-treat principle. We calculated risk ratios (RR) with $95 \%$ confidence intervals $(\mathrm{Cl})$ for the cumulative incidence at each time point, i.e., 1, 3, 6, 12, and 18 months after group assignment. We also performed Poisson regression analyses for the calculated recurrent episode incidence rate ratio (IRR), $95 \% \mathrm{Cl}$, and $\mathrm{p}$ values for outcomes. We used regression models to adjust for the following randomization factors: gender (male vs. female), age (<40 vs. $\geq 40$ years), and history of previous suicide attempts before the current episode (yes vs. no). These factors were reported as strong risk factors in previous studies $[12,13]$. We calculated the distribution of repeat self-harm episodes by group. Statistical analyses were performed using SAS 9.4 (SAS Institute, Inc., Cary, NC, USA) and JMP 10.0.2 (SAS Institute, Inc., Cary, NC, USA).

\section{Results}

A total of 914 eligible adult patients were enrolled in the ACTION-J study. Of these, 460 were randomly assigned to the intervention group and 454 to the control group. Among these groups, there were 297 self-poisoning patients in the intervention group and 295 in the control group (Figure 1).

Baseline characteristics of participants were similar between groups (Table 2). The number of participants with a mood disorder as their primary psychiatric diagnosis was $141(47.5 \%)$ in the intervention group and $143(48.5 \%)$ in the control group. The number of participants with a previous suicide attempt was $172(57.9 \%)$ in the intervention group and $163(55.3 \%)$ in the control group. Finally, the number of participants for whom the suicide attempt leading to their admission to the study was conducted using a pharmaceutical drug prescribed by a doctor was 221 (74.4\%) in the intervention group and 231 (78.3\%) in the control group.

Table 3 shows the incidence of a first recurrent episode after the suicide attempt that led to study admission (follow-up period of 1 month, 3 months, 6 months, 12 months, and 18 months after group assignment) in both groups. The incidence at 6 months was significantly lower in the intervention group than in the control group (RR: $0.473,95 \% \mathrm{Cl}: 0.284$ to 0.788 ). Additionally, the incidence at 1 and 3 months was significantly lower in the intervention group than in the control group.

Table 4 shows the number of repeat suicide attempts and non-suicidal self-harm episodes in both groups during the study period. The number of overall self-harm episodes per person-year was significantly lower in the intervention group than in the control group (IRR: $0.711,95 \% \mathrm{Cl}: 0.582$ to 0.866 ). In addition, both the number of suicide attempts and the number of non-suicidal selfharm episodes were significantly lower in the intervention group than in the control group. Table 5 provides a detailed distribution of repeat self-harm episodes.

\section{Discussion}

Our secondary analysis of data from the ACTION-J study on self-poisoning indicated that assertive case management significantly reduced the incidence of a first recurrent episode within 6 months after group assignment by approximately half. Furthermore, the number of overall self-harm episodes during the entire study period decreased by approximately $20 \%$ in the intervention group. Distribution analysis of the number of self-harm episodes indicated that the effectiveness of assertive case management on repeat self-harm could be attributed to a reduction in the number of patients with multiple repetitions (three or more episodes). We also evaluated the numbers of repeat suicide attempts and non-suicidal self-harm episodes as additional outcomes, and found that the intervention led to a greater reduction of non-suicidal self-harm episodes than suicide attempts. These findings indicate that assertive case management is an effective intervention for self-poisoning as an act of self-harm, irrespective of levels of suicidal intent. Compared with previous reports, these data indicate clearer patterns regarding the effectiveness of assertive case management $[13,14]$.

Several randomized controlled trials have used a case management approach to implement interventions following suicide attempts $[16,17]$. Our data indicate that active contact and follow-up interventions as components of assertive case management programs significantly reduced the proportion of recurrent suicide attempts within 6 months after group assignment by approximately half. However, evidence regarding the effectiveness of interventions in reducing the proportion of recurrent suicide attempts and the number of repeat self-harm episodes is still very limited [17]. Assertive case management used in the present study comprised a comprehensive intervention package. The entire intervention package is needed, as several 
previous studies using partial interventions have failed to show any effectiveness, and any one element of the intervention probably would be no more effective than the other elements. This assertive case management program appears to have an important effect on the engagement of suicidal patients in continuous treatment and care. Further studies will be needed to determine whether the intervention is effective in other settings and regions.

Our study has several strengths. First, this is a secondary analysis of a large randomized controlled multicentre study. Baseline characteristics were well balanced between the intervention and control groups, and also between subgroups (i.e., individuals who engaged in self-poisoning). Second, the trial was conducted in a pragmatic and real-world setting, and high adherence to the intervention was achieved. Third, unlike some previous studies that excluded individuals with certain mental disorders or certain levels of severity, our study included patients with a broad range of mental disorders, as shown in Table 2. Fourth, the primary outcome in this analysis was the incidence of a first recurrent suicide attempt within 6 months after group assignment and the secondary outcomes were the number of overall self-harm episodes per person-year. This enabled us to estimate the effect of the intervention on the overall burden of suicidal behaviour. The number of overall self-harm episodes per person-year is a common outcome among interventional studies of suicide attempts and self-harm, and may be more useful for comparison with other studies than first recurrent suicide attempts, which was also used as the primary outcome in the ACTION-J study [13].

Our focus only on participants who poisoned themselves differentiates our study from previous reports $[13,14]$. The studies by Kawanishi et al. and Furuno et al. used suicidal behaviour data from the complete ACTION-J study, which included all methods of attempted suicide. Self-poisoning is frequently seen in suicide attempters, and, together with self-cutting, is one of the most common methods of self-harm. The method of self-poisoning often includes an addictive element as one of its pathological features, and so self-poisoning may be a very strong predictor of subsequent suicide attempts [18]. Therefore, interventions for self-poisoning and repeated self-poisoning are pivotal in suicide prevention [19]. Previous intervention studies of self-poisoning patients differed in terms of patient background and methodology, resulting in different outcomes [6-11]. Therefore, an intervention for self-poisoning patients based on clear patient background information and a solid study design was needed. For these reasons, we chose to examine the preventive effects of interventions for self-poisoning participants from the ACTION-J study. We also aimed to compare data from self-poisoning patients from the ACTION-J study with data from participants of these previous studies.

The ACTION-J study included only suicide attempters with apparent suicidal intent who were registered after admission to the emergency department for attempted suicide. This approach was taken to increase the feasibility of the intervention study. However, it is not easy to implement an intervention study that incorporates individuals who self-harm, attempt suicide, or have suicidal ideation, given their complicated backgrounds [20]. To implement the intervention consistently, participants from a specific background should be selected. It remains unclear whether the present results are valid for attempted suicide without suicidal intent. This is a topic for a future study.

Our study also has several limitations. First, we excluded patients younger than 20 years for ethical reasons. However, self-harm is common and highly recurrent in adolescents [21]. Patients who engaged in self-harm but were not admitted to an emergency department were also excluded from our study. In view of these exclusion criteria, the study population may differ somewhat from the general population of patients who engage in self-harm and are admitted to emergency departments, as well as from the populations assessed in some previous studies. Second, we excluded participants who did not meet the criteria for suicidal intent. As we adopted relatively stringent criteria for suicidal intent, we may have excluded participants who potentially would have been eligible to participate in other studies relating to suicidal behaviour. This difference in criteria may affect the comparability of our study with others. Third, differences in existing medical resources or social support between countries may influence the effect of interventions. This should be taken into account when similar interventions are implemented outside Japan.

\section{Conclusion}

Our secondary analysis of data from the ACTION-J study indicated that assertive case management following emergency admission for a suicide attempt by self-poisoning reduced the proportion of suicide attempts during the 6-month period following group assignment. Moreover, the intervention reduced the incidence of repeat overall self-harm episodes during the entire study 
period. These findings suggest that assertive case management is an effective intervention when promptly introduced in a hospital setting following a suicide attempt, and that this intervention is especially effective for self-poisoning patients.

\section{Abbreviations}

\section{ACTION-J}

A Randomized Controlled Multicentre Trial of Post-Suicide Attempt Case Management for the Prevention of Further Attempts in Japan; DSM-IV-TR:Diagnostic and Statistical Manual of Mental Disorders-IV-Text Revision; Cl:confidence interval; RR:risk ratio; IRR:incidence rate ratio.

\section{Declarations}

\section{Ethics approval and consent to participate}

The study protocol was approved by the Central Research Ethics Committee of the study sponsor (Japan Foundation for Neuroscience and Mental Health, Tokyo, Japan) and by the local ethics committees of all participating hospitals. This study is registered at ClinicalTrials.gov (NCT00736918) and UMIN-CTR (C000000444).

\section{Consent for publication}

Not applicable.

\section{Availability of data and materials}

All data generated or analysed during this study are included in this published article.

\section{Competing interests}

The authors declare that they have no competing interests.

\section{Funding}

This study was funded by the Ministry of Health, Labour and Welfare (H17-kokoro- senryaku-030), Japan, and the Japan Agency for Medical Research and Development (118dk0307057h0003). Neither the funder nor the sponsor of the study had any role in the design of the study, the collection, analysis, and interpretation of data, and the writing of the manuscript.

\section{Authors' contributions}

$\mathrm{YH}, \mathrm{CK}$, and NY conceived and designed the study. YH was the principal investigator. YK, KY, HM, and MT enrolled patients. MT was the study case manager. $\mathrm{Ml}$ and $\mathrm{KY}$ were the study outcome assessors. $\mathrm{CK}$, KO, and $\mathrm{HT}$ managed the study at participating sites. NY analysed the data. MIY wrote the first draft of the manuscript. YH, HT, KO, CK, NY, MT, YK, KY, and HM contributed to the writing of the manuscript.

\section{Acknowledgements}

We thank Mitsuhiko Yamada from the National Centre of Neurology and Psychiatry (Tokyo, Japan) and Masatoshi Inagaki from Shimane University Hospital (Shimane, Japan) for their helpful input.

\section{References}

1. Cambridge DR, Wood RJ, Bateman DN. The epidemiology of self-poisoning in the UK. Br J Clin Pharmacol. 2003;56:613-9.

2. Hawton K, Harriss L, Hall S, Simkin S, Bale E, Bond A. Deliberate self-harm in Oxford, 1990-2000. A time of change in patient characteristics. Psychol Med. 2003;33:987-95. 
3. Ting SA, Sullivan AF, Boudreaux ED, Miller I, Camargo CA Jr. Trends in US emergency department visits for attempted suicide and self-inflicted injury, 1993-2008. Gen Hosp Psychiatry. 2012;34:557-65.

4. Bergen $\mathrm{H}$, Hawton K, Waters K, Cooper J, Kapur N. Epidemiology and trends in non-fatal self-harm in three centres in England: 2000-2007. Br J Psychiatry. 2010;197:493-8.

5. Bilen K, Ottosson C, Castren M, Ponzer S, Ursing C, Ranta P, Ekdahl K, Pettersson H. Deliberate self-harm patients in the emergency department: factors associated with repeated self-harm among 1524 patients. Emerg Med J. 2011;28:1019-25.

6. Carter GL, Clover K, Whyte IM, Dawson AH, D'Este C. Postcards from the EDge project: randomised controlled trial of an intervention using postcards to reduce repetition of hospital treated deliberate self poisoning. BMJ. 2005;331:805-7.

7. Carter GL, Clover K, Whyte IM, Dawson AH, D’Este C. Postcards from the EDge: 24-month outcomes of a randomised controlled trial for hospital-treated self-poisoning. Br J Psychiatry. 2007;191:548-53.

8. Carter GL, Clover K, Whyte IM, Dawson AH, D'Este C. Postcards from the EDge: 5-year outcomes of a randomised controlled trial for hospital treated self-poisoning. Br J Psychiatry. 2013;202:372-80.

9. Hassanian-Moghaddam H, Sarjami S, Kolahi AA, Carter GL. Postcards in Persia: randomised controlled trial to reduce suicidal behaviours 12 months after hospital-treated self-poisoning. Br J Psychiatry. 2011;198:309-16.

10. Vaiva G, Ducrocq F, Meyer P, Mathieu D, Philippe A, Libersa C, Goudemand M. Effect of telephone contact on further suicide attempts in patients discharged from an emergency department: randomised controlled study. BMJ. 2006;332:1241-5.

11. Guthrie E, Kapur N, Mackway-Jones K, Chew-Graham C, Moorey J, Mendel E, Marino-Francis F, Sanderson S, Turpin C, Boddy $\mathrm{G}$, Tomenson B. Randomised controlled trial of brief psychological intervention after deliberate self poisoning. BMJ. 2001;323:135-8.

12. Hirayasu Y, Kawanishi C, Yonemoto N, Ishizuka N, Okubo Y, Sakai A, Kishimoto T, Miyaoka H, Otsuka K, Kamijo Y, Matsuoka $Y$, Aruga T. A randomized controlled multicenter trial of post-suicide attempt case management for the prevention of further attempts in Japan (ACTION-J). BMC Public Health. 2009;9:364.

13. Kawanishi C, Aruga T, Ishizuka N, Yonemoto N, Otsuka K, Kamijo Y, Okubo Y, Ikeshita K, Sakai A, Miyaoka H, Hitomi Y, Iwakuma A, Kinoshita T, Akiyoshi J, Horikawa N, Hirotsune H, Eto N, Iwata N, Kohno M, Iwanami A, Mimura M, Asada T, Hirayasu Y. Assertive case management versus enhanced usual care for people with mental health problems who had attempted suicide and were admitted to hospital emergency departments in Japan (ACTION-J): a multicentre, randomised controlled trial. Lancet Psychiatry. 2014;1:193-201.

14. Furuno T, Nakagawa M, Hino K, Yamada T, Kawashima Y, Matsuoka Y, Shirakawa O, Ishizuka N, Yonemoto N, Kawanishi C, Hirayasu Y. Effectiveness of assertive case management on repeat self-harm in patients admitted for suicide attempt: Findings from ACTION-J study. J Affect Disord. 2018;225:460-5.

15. Beck A, Schuyler D, Herman J. Development of suicidal intent scales. In: Beck A, Resnik H, Lettieri DJ, editors. The Prediction of Suicide. Bowie: Charles Press; 1974. pp. 45-56.

16. Hawton K, Witt KG, Salisbury TLT, Arensman E, Gunnell D, Hazell P, Townsend E, van Heeringen K. Psychosocial interventions following self-harm in adults: a systematic review and meta-analysis. Lancet Psychiatry. 2016;3:740-50.

17. Inagaki M, Kawashima Y, Yonemoto N, Yamada M. Active contact and follow-up interventions to prevent repeat suicide attempts during high-risk periods among patients admitted to emergency departments for suicidal behavior: a systematic review and meta-analysis. BMC Psychiatry. 2019;19:44.

18. Finkelstein Y, Macdonald EM, Hollands S, Sivilotti ML, Huston JR, Mamdani MM, Koren G, Juurlink DN. Canadian Drug Safety and Effectiveness Research Network (CDSERN). Risk of suicide following deliberate self-poisoning. JAMA Psychiatry. 2015;72:570-5.

19. Kapur N, Turnbull P, Hawton K, Simkin S, Sutton L, Mackway-Jones K, Bennewith O, Gunnell D. Self-poisoning suicides in England: a multicentre study. QJM. 2005;98:589-97.

20. Mann JJ, Apter A, Bertolote J, Beautrais A, Currier D, Haas A, Hegerl U, Lonnqvist J, Malone K, Marusic A, Mehlum L, Patton G, Phillips M, Rutz W, Rihmer Z, Schmidtke A, Shaffer D, Silverman M, Takahashi Y, Varnik A, Wasserman D, Yip P, Hendin H. Suicide prevention strategies: a systematic review. JAMA. 2005;294:2064-74.

21. Hawton K, Saunders KEA, O’Connor RC. Self-harm and suicide in adolescents. Lancet. 2012;379:2373-82. 


\section{Tables}

Table 1. Clinical trials that targeted selfpoisoning.

\begin{tabular}{|c|c|c|c|c|c|}
\hline & $\begin{array}{l}\text { Method } \\
\text { (study period) }\end{array}$ & $\begin{array}{l}\text { Intervention } \\
\text { group }\end{array}$ & $\begin{array}{l}\text { Control } \\
\text { group }\end{array}$ & $\begin{array}{l}\text { Primary and secondary } \\
\text { outcomes }\end{array}$ & Summary of results \\
\hline $\begin{array}{l}\text { Carter et al. } \\
(2005,2007 \text {, } \\
2013)\end{array}$ & $\begin{array}{l}\text { Sending } \\
\text { postcards }(12, \\
24,60 \\
\text { months })\end{array}$ & $n=378$ & $\begin{array}{l}n= \\
394\end{array}$ & $\begin{array}{l}\text { Self-poisoning } \\
\text { admissions and } \\
\text { psychiatric admissions } \\
\text { (proportions and event } \\
\text { rates). }\end{array}$ & $\begin{array}{l}\text { No difference between rate of } \\
\text { self-poisoning admission and } \\
\text { psychiatric admission. A } \\
\text { significant reduction in repetition } \\
\text { of hospital-treated self-poisoning } \\
\text { events rates. }\end{array}$ \\
\hline $\begin{array}{l}\text { Hassanian- } \\
\text { Moghaddam } \\
\text { et al. (2011) }\end{array}$ & $\begin{array}{l}\text { Sending } \\
\text { postcards (12 } \\
\text { months) }\end{array}$ & $n=1043$ & $\begin{array}{l}\mathrm{n}= \\
1070\end{array}$ & $\begin{array}{l}\text { Suicidal ideation, } \\
\text { suicide attempts, and } \\
\text { self-cutting (proportions } \\
\text { and event rates). }\end{array}$ & $\begin{array}{l}\text { Significant reduction in suicidal } \\
\text { ideation, suicide attempts, and } \\
\text { number of attempts. No } \\
\text { significant reduction in self- } \\
\text { cutting or self-cutting events. }\end{array}$ \\
\hline $\begin{array}{l}\text { Vaiva et al. } \\
(2006)\end{array}$ & $\begin{array}{l}\text { Telephone } \\
\text { call from a } \\
\text { psychiatrist at } \\
1 \text { or } 3 \\
\text { months (13 } \\
\text { months) }\end{array}$ & $\begin{array}{l}\mathrm{n}=147(1 \\
\text { month) } \\
\mathrm{n}=146(3 \\
\text { months })\end{array}$ & $\begin{array}{l}\mathrm{n}= \\
312\end{array}$ & $\begin{array}{l}\text { Proportion of } \\
\text { participants who } \\
\text { reattempted suicide, } \\
\text { number of deaths by } \\
\text { suicide, and loss of } \\
\text { contact at the 13-month } \\
\text { point. }\end{array}$ & $\begin{array}{l}\text { No significant differences in rates } \\
\text { of further suicide attempts, } \\
\text { deaths by suicide, or loss of } \\
\text { contact among three groups. }\end{array}$ \\
\hline $\begin{array}{l}\text { Guthrie et al. } \\
(2001)\end{array}$ & $\begin{array}{l}\text { Brief } \\
\text { psychological } \\
\text { intervention ( } 6 \\
\text { months) }\end{array}$ & $\mathrm{n}=58$ & $\mathrm{n}=61$ & $\begin{array}{l}\text { Severity of suicidal } \\
\text { ideation } 6 \text { months after } \\
\text { treatment as assessed } \\
\text { by the Beck scale for } \\
\text { suicidal ideation. }\end{array}$ & $\begin{array}{l}\text { Significantly greater reduction in } \\
\text { the intervention group. }\end{array}$ \\
\hline
\end{tabular}

There are some previous investigations after a first recurrent episode of self-poisoning. However, in these preceding investigations, there are some issues regarding differences in patient background. They also differ in methodology, and consequently resulted in different outcomes. 
Table 2. Baseline characteristics.

\begin{tabular}{|c|c|c|}
\hline & Intervention group & $\begin{array}{l}\text { Control } \\
\text { group }\end{array}$ \\
\hline & $(n=297)$ & $(n=295)$ \\
\hline Mean age (SD) & $41.59(13.91)$ & $\begin{array}{l}40.98 \\
(15.37)\end{array}$ \\
\hline \multicolumn{3}{|l|}{ Gender, n (\%) } \\
\hline Male & $105(35.4 \%)$ & $\begin{array}{l}113 \\
(38.3 \%)\end{array}$ \\
\hline Female & $192(64.6 \%)$ & $\begin{array}{l}182 \\
(61.7 \%)\end{array}$ \\
\hline \multicolumn{3}{|l|}{ Primary psychiatric diagnosis, n (\%) } \\
\hline Substance-related disorder & $12(4.0 \%)$ & $14(4.8 \%)$ \\
\hline Schizophrenia or other psychotic disorder & $49(16.5 \%)$ & $48(16.3 \%)$ \\
\hline Mood disorder & $141(47.5 \%)$ & $\begin{array}{l}143 \\
(48.5 \%)\end{array}$ \\
\hline Adjustment disorder & $72(24.2 \%)$ & $67(22.7 \%)$ \\
\hline Other & $23(7.7 \%)$ & $23(7.8 \%)$ \\
\hline \multicolumn{3}{|l|}{ Previous suicide attempt, n (\%) } \\
\hline None & $125(42.1 \%)$ & $\begin{array}{l}132 \\
(44.8 \%)\end{array}$ \\
\hline One or more & $172(57.9 \%)$ & $\begin{array}{l}163 \\
(55.3 \%)\end{array}$ \\
\hline \multicolumn{3}{|l|}{ Method of present suicide attempt, n (\%) } \\
\hline Pharmaceutical drug prescribed by doctor & $221(74.4 \%)$ & $\begin{array}{l}231 \\
(78.3 \%)\end{array}$ \\
\hline Psychotropic drug & $208(70.0 \%)$ & 212 \\
\hline Other drug & $29(9.8 \%)$ & $36(12.2 \%)$ \\
\hline OTC drug & $49(16.5 \%)$ & $37(12.5 \%)$ \\
\hline Poison & $56(18.9 \%)$ & $54(18.3 \%)$ \\
\hline \multicolumn{3}{|c|}{ Baseline characteristics of participants were similar between groups. } \\
\hline \multicolumn{3}{|c|}{$\begin{array}{l}\text { Multiple answers were shown in method of present suicide attempt because some individuals used more than } \\
\text { one method. }\end{array}$} \\
\hline Abbreviations: OTC drug over-the-counter dru & & \\
\hline
\end{tabular}


Table 3. Effects on first recurrent episodes after attempted suicide in intervention and control groups.

\begin{tabular}{|c|c|c|c|c|c|c|c|c|c|c|c|}
\hline & & $\begin{array}{l}\text { Intervention } \\
\text { group }\end{array}$ & $\begin{array}{l}\text { Control } \\
\text { group }\end{array}$ & & & & & & & & \\
\hline & & $\mathrm{n} / \mathrm{N}$ & $\mathrm{n} / \mathrm{N}$ & $\mathrm{RR}$ & $95 \% \mathrm{Cl}$ & & $\begin{array}{l}\mathrm{P}- \\
\text { value }\end{array}$ & $\begin{array}{l}\text { Adjusted } \\
\text { RR }\end{array}$ & $95 \% \mathrm{Cl}$ & & $\begin{array}{l}\text { P- } \\
\text { value }\end{array}$ \\
\hline $\begin{array}{l}\text { Primary } \\
\text { outcome }\end{array}$ & $\begin{array}{l}6 \\
\text { months }\end{array}$ & $19 / 269$ & $41 / 280$ & 0.480 & 0.288 & 0.809 & 0.0059 & 0.473 & 0.284 & 0.788 & 0.004 \\
\hline \multirow[t]{4}{*}{$\begin{array}{l}\text { Other } \\
\text { outcomes }\end{array}$} & $\begin{array}{l}1 \\
\text { month }\end{array}$ & $2 / 287$ & $11 / 289$ & 0.180 & 0.041 & 0.819 & 0.0210 & 0.173 & 0.039 & 0.774 & 0.0217 \\
\hline & $\begin{array}{l}3 \\
\text { months }\end{array}$ & $5 / 277$ & $26 / 285$ & 0.200 & 0.077 & 0.508 & 0.0001 & 0.194 & 0.076 & 0.497 & 0.0006 \\
\hline & $\begin{array}{l}12 \\
\text { months }\end{array}$ & $32 / 252$ & $49 / 260$ & 0.670 & 0.447 & 1.016 & 0.0689 & 0.690 & 0.461 & 1.032 & 0.071 \\
\hline & $\begin{array}{l}18 \\
\text { months }\end{array}$ & $39 / 237$ & $57 / 248$ & 0.720 & 0.496 & 1.033 & 0.0870 & 0.722 & 0.505 & 1.033 & 0.0744 \\
\hline \multicolumn{12}{|c|}{$\begin{array}{l}\text { We calculated the incidence of a first recurrent suicidal attempt within } 6 \text { months after group assessment as the primary } \\
\text { outcome measure. The incidence at } 1,3 \text {, and } 6 \text { months was significantly lower in the intervention group than in the control } \\
\text { group. }\end{array}$} \\
\hline
\end{tabular}

Table 4. Repeat suicide attempts and episodes as influenced by non-suicidal self-harm during the study period.

\begin{tabular}{|lllll|}
\hline & Adjusted IRR & $95 \% \mathrm{Cl}$ & & P-value \\
\hline Overall self-harm & 0.711 & 0.582 & 0.866 & 0.0007 \\
\hline Suicide attempts & 0.752 & 0.578 & 0.976 & 0.0321 \\
\hline Non-suicidal self-harm & 0.659 & 0.484 & 0.892 & 0.0069
\end{tabular}

The number of overall self-harm episodes per person-year was significantly lower in the intervention group than in the control group (IRR $0.711,95 \% \mathrm{Cl} 0.582$ to 0.866 ). In addition, both the number of suicide attempts and the number of non-suicidal self-harm episodes were significantly lower in the intervention group compared with the control group.

Abbreviations: IRR incidence rate ratio, $\mathrm{Cl}$ confidence interval. 


\begin{tabular}{|c|c|c|c|c|}
\hline & 0 & 1 & 2 & $\geq 3$ \\
\hline \multicolumn{5}{|l|}{ Overall self-harm } \\
\hline Intervention group $(\mathrm{n}=297)$ & $215(72.4)$ & $46(15.5)$ & $22(7.4)$ & $14(4.7)$ \\
\hline Control group $(n=295)$ & $215(72.9)$ & $40(13.6)$ & $11(3.7)$ & $29(9.8)$ \\
\hline \multicolumn{5}{|l|}{ Suicide attempts } \\
\hline Intervention group $(\mathrm{n}=297)$ & $237(79.8)$ & $45(15.2)$ & $10(3.4)$ & $5(1.7)$ \\
\hline Control group $(n=295)$ & $230(78.0)$ & $37(12.5)$ & $11(3.7)$ & $17(5.8)$ \\
\hline \multicolumn{5}{|l|}{ Non-suicidal self-harm } \\
\hline Intervention group $(\mathrm{n}=297)$ & $255(85.9)$ & $26(8.8)$ & $12(4.0)$ & $5(1.7)$ \\
\hline Control group $(n=295)$ & $258(87.5)$ & $17(5.8)$ & $7(2.4)$ & $13(4.4)$ \\
\hline \multicolumn{5}{|c|}{$\begin{array}{l}\text { We calculated the distribution of repeat self-harm episodes by group. The number of individuals with three or more episodes } \\
\text { of overall self-harm during the follow-up period was } 14(4.7 \%) \text { in the intervention group and } 29(9.8 \%) \text { in the control group. } \\
\text { The number of individuals with three or more episodes of non-suicidal self-harm during the follow-up period was } 5(1.7 \%) \text { in } \\
\text { the intervention group and } 13(4.4 \%) \text { in the control group. }\end{array}$} \\
\hline
\end{tabular}

\section{Figures}




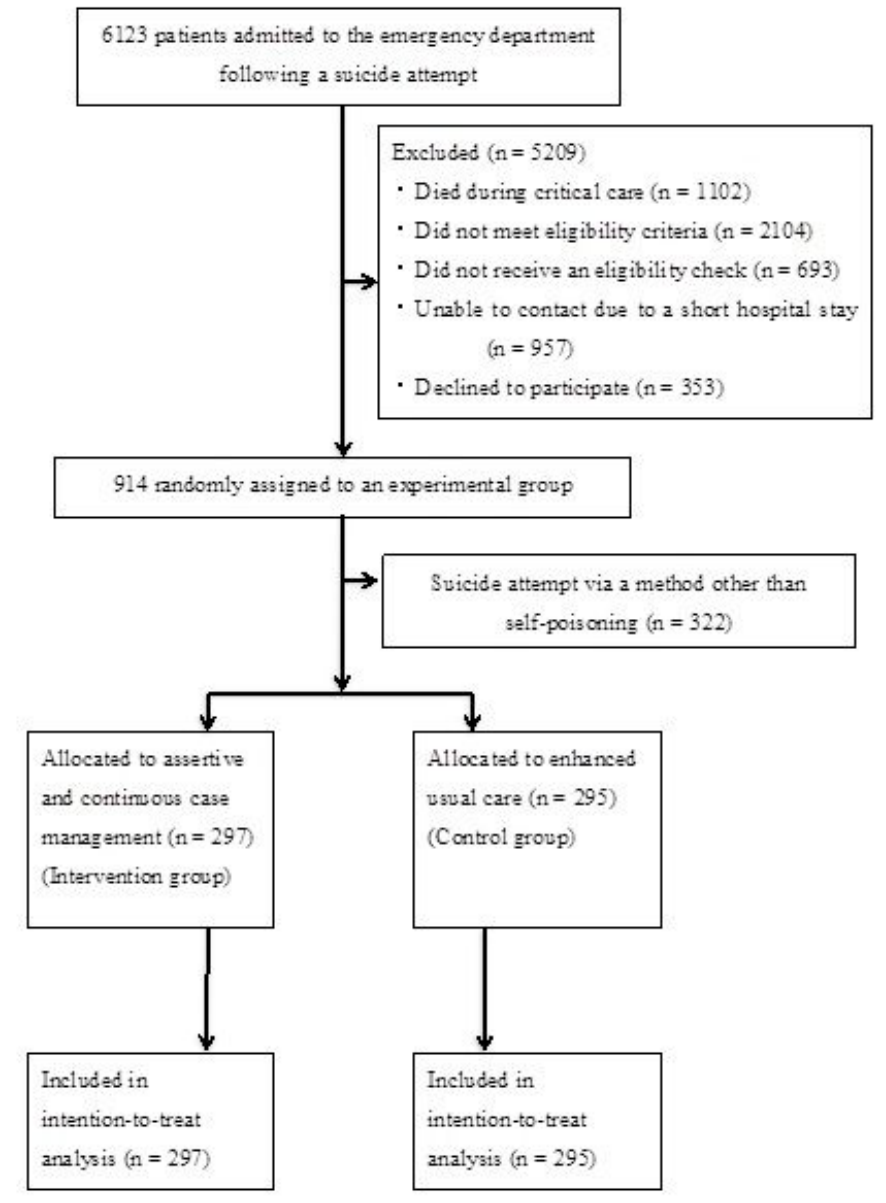

Figure 1. Flow chart of participant selection. 6123 patients were admitted to emergency departments between July 1, 2006, and December 31, 2009 after suspected suicide attempts. A total of 914 eligible patients (aged -20 years) were enrolled. Of these, 592 self-poisoning patients were randomly assigned to the intervention group $(n=297)$ and the control group $(n=295)$.

\section{Figure 1}

Flowchart of participant selection. 